\title{
Lizards slay Lyme disease spirochetes
}
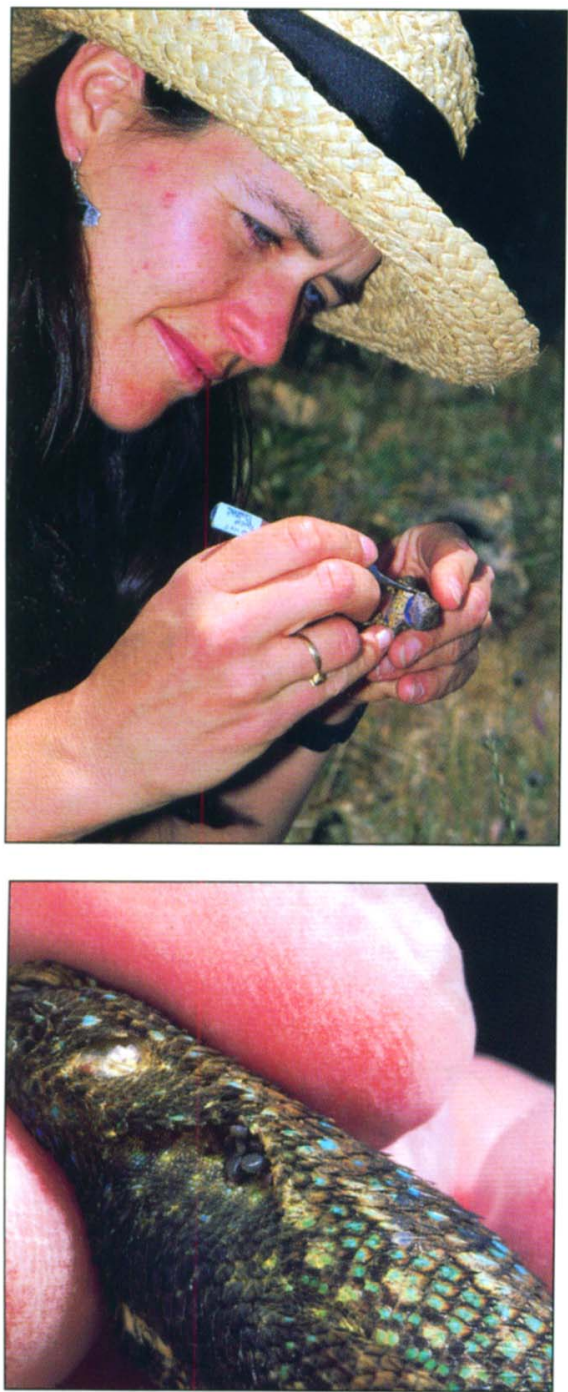

Top, staff research assistant Kerry Padgett plucks a tick off a western fence lizard. Above, ticks feeding on the lizard's blood can be cleansed of the Lyme disease bacterium.
Ticks harboring the Lyme disease infection when they feed on the blood of the common western fence lizard, UC Berkeley researchers have discovered.

The scientists reported their work in the February issue of the Journal of Parasitology. They speculate the new finding may help explain why Lyme disease is less common in California but epidemic in some northeastern states, where lizards are rare.

"Lizards are doing humanity a great service here," says Robert Lane, professor of insect biology at UC Berkeley and principal investigator on the tick project. "The lizard's blood contains a substance - probably a heat-sensitive protein - that kills the Lyme disease spirochete, a kind of bacterium."

Even better news, the newly discovered protein apparently leaches into the mid-gut of infected nymphal ticks as the tick feeds and destroys spirochetes stored there, permanently cleansing the ticks before they mature to adults.

Nymphal ticks feed abundantly on the lizards, and in some habitats in Northern California, lizards are more numerous than rodents. Unlike wood rats and some other wild rodents, western fence lizards produce the newly discovered "spirochete-killing factor," not yet identified.

In California, the western blacklegged tick is the primary carrier of Borrelia burgdorferi, the bacterium causing Lyme disease. The nymphal tick is an immature stage about the size of a poppy seed. These tiny ticks can do big damage, causing most cases of Lyme disease in the state, where the disease occurs in people who frequent tick-infested areas during the spring and summer.

Some populations of western black-legged ticks are three to four times more likely to carry the dangerous Lyme disease spirochete as nymphs than as adults. This is contrary to logic, since "you would expect that the older the tick is, the more likely it is to be infected," says Lane. "To reach the adult stage, a tick must have fed twice before, whereas to reach the nymphal stage, it must have fed only once," leaving less opportunity for exposure to infection.

Lane's recent study of Tilden Regional Park in Berkeley showed that in one area $1.3 \%$ of adult ticks carry the Lyme-disease bacterium, compared to $5.7 \%$ of nymphal ticks. These rates are much lower than in the northeastern United States, where, for instance, $50 \%$ of adult ticks and $25 \%$ of nymphal ticks carry the bacterium.

Lane points out that along most of the trails surveyed at Tilden, the infection rate in adult ticks was even lower, as low as $0 \%$ in some areas. Picnic areas yielded few ticks year-round, showing the risk there is lower than along trails. All in all, the risk of being infected with Lyme disease from a tick bite in Tilden is very low.

Nymphal ticks are most active from April through July, Lane says. They live in shady, moist wooded areas carpeted with dead leaves and organic matter. People are most likely to acquire Lyme disease from nymphal ticks while gardening, picnicking, resting or otherwise enjoying the outdoors in such areas.

"Because of their small size, nymphal ticks are hard to detect on human skin," says Lane. "You could easily have them and not know it. Probably no more than 20 to $30 \%$ of people who acquire Lyme disease as a result of a nymphal bite are aware that they've been bitten."

Nymphal ticks feed fully within about 3 to 5 days, but most of the blood meal is not ingested until the final day of feeding. Therefore, they remain small until just before they detach and drop off the host, which explains why tick-bite victims often don't notice them. Also, people may be bitten in inconspicuous areas, such as the scalp, and the bite is typically painless.

Lane collaborated with UC Berkeley researcher Gary Quistad on the recent work, funded by the National Institutes of Health. -Kathleen Scalise

(In other work, Lane reports on a method to rid wood rats of ticks. See page 43.-Ed.) 